\title{
Consumer loyalty of Indonesia e-commerce SMEs: The role of social media marketing and cus- tomer satisfaction
}

\author{
Suharto $^{a^{*}}$, I Wayan Ruspendi Junaedi ${ }^{\text {b }}$, H.M. Muhdarc, Arif Firmansyah ${ }^{\text {d,e }}$ and Sarana $^{\text {a }}$
}

\author{
${ }^{a}$ Politeknik Negeri Semarang, Indonesia \\ ${ }^{b}$ Universitas Dhyana Pura Bali, Indonesia \\ ${ }^{c}$ IAIN Sultan Amai Gorontalo, Indonesia \\ ${ }^{d}$ Universitas Airlangga, Indonesia \\ Article history: \\ Received: October 20, 2021 \\ Received in revised format: No- \\ vember 18,2021 \\ Accepted: December 27, 2021 \\ Available online: December 27, \\ 2021 \\ Keywords: \\ Social media marketing \\ Satisfaction \\ Loyalty \\ e-commerce customers
}

${ }^{e}$ GITM National Chung Hsing University, Taiwan

\section{A B S T R A C T}

\begin{abstract}
The purpose of this study is to analyze the influence of social media marketing on e-commerce customer satisfaction and loyalty. This study provides insight into the importance of consumer loyalty in the e-commerce industry. The approach used in this study uses quantitative methods through surveys. This study uses a sample of 222 respondents of e-commerce customers. The study uses an online questionnaire through Google Docs. The questionnaire given contains structured questions that are limited by screening, profiling questions and questions related to research variables that affect e-commerce consumer loyalty. The distribution of the questionnaires was carried out by posting on social media groups and direct messages to respondents in accordance with the research requirements. Data analysis of this research, using SEM model using SmartPLS 3.0 software. The results of this study indicate that social media marketing had a significant effect on e-commerce consumer satisfaction, social media marketing had a significant effect on e-commerce consumer loyalty and satisfaction had a significant effect on e-commerce consumer loyalty.
\end{abstract}

\section{Introduction}

The development of the internet in Indonesia is currently experiencing a significant increase. The growth of internet users tends to increase consistently over a long period of time. Internet user penetration in Indonesia in 2019 was 171.17 million people or $64.8 \%$ of the total population. The social media most frequently used by the public are Instagram 50.7\%, Facebook $17.8 \%$, Twitter $16.4 \%$, and Youtube $15.1 \%$. In line with internet penetration, this has an impact on the progress of the ecommerce business. This is because the e-commerce platform can only be used when the user is connected to an internet connection. According to Arghashi et al. (2021) and Azizan et al. (2019), social media marketing is defined as the use of social media technology to communicate, deliver and exchange offerings that have value for the organization's stakeholders. Social media marketing is the use of social media in marketing products and services through social media tools such as Blogs, Facebook, twitter, Instagram, Youtube, social media is considered as part of integrated marketing communication by providing a platform that allows interaction between fellow users. Social media can be an effective strategy to reach and engage potential consumers, as well as encourage interaction between companies and consumers, and between consumers themselves. The research of Barreda et al. (2020), Bilgin et al. (2018) showed that the popularity of social media today could be a business strategy. This is due to the high intensity of the use of social media, and the efficiency of marketing costs. According to Pramono et al.( (2021), Rudyanto et al. (2021), Wijayaa et al.( (2021) and Yuliantoro et al.( (2019), social media marketing

* Corresponding author.

E-mail address: pakharto58@gmail.com (Suharto)

(C) 2022 by the authors; licensee Growing Science, Canada. doi: $10.5267 /$ j.ijdns.2021.12.016 
is defined as a process carried out by companies in communicating and conducting online marketing activities through social media platforms to build and maintain stakeholder relationships by interacting, sharing information, and recommending purchases. According to Arghashi et al. (2021), Azizan et al. (2019), Barreda et al. (2020), Bilgin et al. (2018) there are four dimensions of social media marketing, namely: interactivity, personalization, informativeness, and word-of-mouth (WOM). According to Nobar et al. (2020), Pham et al. (2015), Savitri et al. (2022) and Seo et al. (2020), interactivity refers to the customer's perception of the extent to which social media e-commerce facilitates customers to share content and views with other companies and customers. Second, personalization refers to customer perceptions of the extent to which e-commerce social media offers content and services that match customer preferences. Third, informativeness is the customer's perception of the extent to which e-commerce social media offers accurate, useful, and comprehensive information. The last is word-ofmouth which refers to the perception of customers to recommend and share experiences with products and services consumed through social media.

Loyalty is a customer's commitment to repeat purchases on a regular basis (Peelen, 2005). Customer loyalty is defined as the willingness of customers to use and buy products or services at one company repeatedly, not easily influenced by other brands, and voluntarily introduce these products and services to others. Loyalty is a commitment owned to buy and use the same product or service. Customers who repeatedly go to the same place to satisfy a wish by obtaining and paying for a product or service. Arghashi et al. (2021), Azizan et al. (2019), Barreda et al. (2020), Bilgin et al. (2018) define customer loyalty as a commitment held by customers to repurchase products or services continuously in the future. If organizations wish to have a lot of loyal customers, they need to provide social and financial benefits to their customers. Loyalty can be built by establishing long-term relationships, providing incentives, managing customer complaints, and encouraging customer feedback. According to Nobar et al. (2020), Pham et al. (2015), Savitri et al. (2022) and Seo et al. (2020), strategies to increase customer loyalty can maintain long-term relationships, reduce marketing costs, and enrich sales.

The purpose of this study is to analyze the influence of social media marketing on e-commerce customer satisfaction and loyalty. This study provides insight into the importance of consumer loyalty in the e-commerce industry.

\section{Hypotheses Development}

According to Savitri et al. (2022), Seo et al. (2020), social media marketing has a significant influence on satisfaction. The implementation of marketing programs through social media has proven to be effective in creating profitable relationships with consumers. This is supported by research According to Nobar et al. (2020) and Pham et al. (2015) that social media marketing involves consumers to interact and collaborate with companies. This can build closeness and maintain relationships with consumers. Consumer involvement will have a good impact on the company. Zaryab et al. (2019) conducted a study to analyze the effect of social media marketing on satisfaction in the e-commerce industry. The results of this study reveal that social media marketing has a positive and significant influence on e-commerce customer satisfaction. Based on the exposure of the previous research, the hypotheses to be tested are:

\section{H1: Social media marketing has a significant effect on e-commerce consumer satisfaction.}

According to Nobar et al. (2020), social media marketing has a positive and significant effect on online shopping consumer loyalty. According to Pham et al. (2015), Savitri et al. (2022) and Seo et al. (2020) online-based companies must show a genuine interest in increasing customer satisfaction and trust in online shopping. When customers are satisfied with the services provided, it can increase customer confidence in the goods they consume. Based on the exposure of the previous research, the hypotheses to be tested are:

\section{H2: Social media marketing has a significant effect on e-commerce consumer loyalty.}

Jamali et al. (2018), Judson et al. (2012), Musa et al. (2016), Nisar et al. (2016) conducted research on the effect of satisfaction on customer loyalty. The results of the study revealed that customer satisfaction can lead to loyalty. This is because consumers tend to reduce the risk of trying new brands, so these consumers prefer to continue to consume products and services that provide an experience in accordance with consumer expectations. The results of this study indicate that satisfaction is the main key and starting point of loyalty. Based on the exposure of the previous research, the hypotheses to be tested are:

H3: Satisfaction has a significant effect on e-commerce consumer loyalty.

\section{Method}

Respondent data collection was carried out in Indonesia in 2021. The approach used in this study used quantitative methods through surveys. This study used a total sample of 222 respondents. This study uses an online questionnaire through Google Docs. The questionnaire given contains structured questions that are limited by screening, profiling questions and questions related to research variables that affect e-commerce consumer loyalty. The distribution of the questionnaires was carried out by posting on social media groups and direct messages to respondents in accordance with the research requirements. Data 
analysis of this research, using SEM model using SmartPLS 3.0 software. The stages of analyzing the influence of social media marketing on e-commerce consumer loyalty through brand image and relationship marketing are measured using the SEM model. According to Hair et al. (2017) the suitability evaluation was carried out through several stages, namely 1) the overall fit of the model; 2) the fit of the measurement model; 3) structural model fit. Fig. 1 shows the structure of the proposed study.

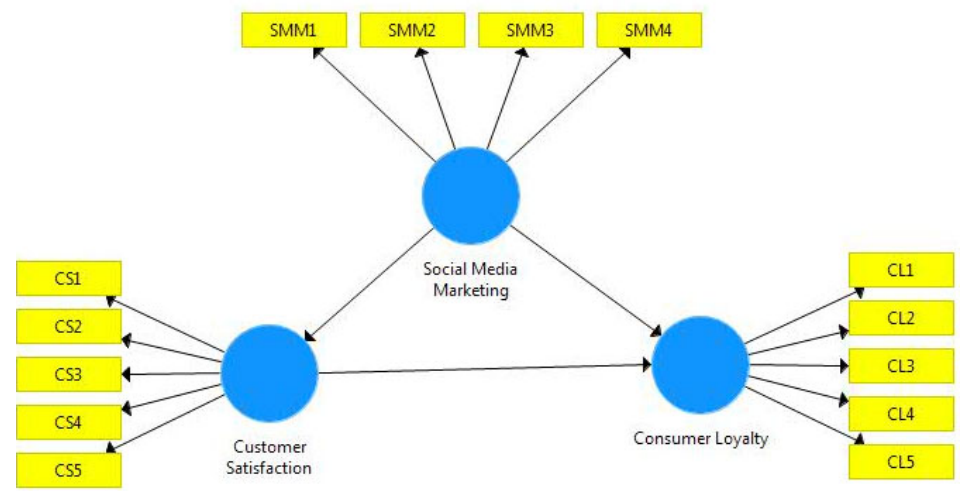

Fig. 1. Research Model

\section{Result and Discussion}

The tests carried out in the analysis of variance-based SEM have two stages, namely the outer model and the inner model test. The explanation of the test is as follows:

\section{Test Outer Model}

The convergent validity test on the outer model aims to determine whether the indicators with latent variables are valid, with a validity value above 0.70 (Purwanto et al., 2021).

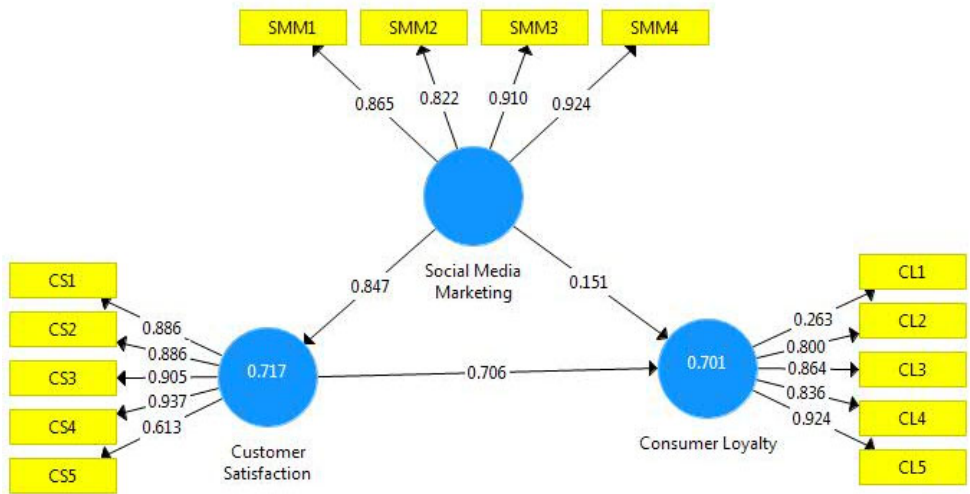

Fig. 2. Convergent Testing

Fig. 2 shows that the validity value of each indicator is above 0.7 , so all research indicators are declared valid. In the outer model test in addition to convergent validity, there is also a validity reliability test. The test aims to determine the reliability of the indicator in measuring the variable, while the variable is said to be valid if it has an AVE value above 0.5 and a Cronbach Alpha value above 0.7 (Purwanto et al., 2021), the following is a discriminant validity test in this study:

Table 1

Average Variance Extracted (AVE)

\begin{tabular}{llll}
\hline Variables & Cronbach's Alpha & Composite Reliability & Average Variance Extracted (AVE) \\
\hline Customer Loyalty & 0.770 & 0.867 & 0.687 \\
Customer Satisfaction & 0.748 & 0.853 & 0.66 \\
Social Media Marketing & 0.793 & 0.879 & 0.707 \\
\hline
\end{tabular}

Table 1 shows that all Cronbach alpha and average variance extracted values exceed the minimum limit so that all variables are declared valid. 


\section{Inner model test}

The inner model test contains an explanation of the R-Square, while the R-square value in this study is as follows:

\section{Table 2}

R Square

\begin{tabular}{lll}
\hline Variables & R Square & R Square Adjusted \\
\hline Customer Loyalty & 0.717 & 0.709 \\
Customer Satisfaction & 0.701 & 0.689 \\
\hline
\end{tabular}

From the R square table, it can be concluded that $71.7 \%$ customer loyalty is influenced by Social Media Marketing and customer satisfaction, while the remaining $28.53 \%$ is influenced by other variables outside the study. Customer satisfaction variable is influenced by social media marketing by $70.1 \%$ while the remaining $29.8 \%$ is influenced by other factors outside the theme of this study. In addition to reliability in the inner model test, there is also a hypothesis test, while the hypothesis testing in this study is as follows:

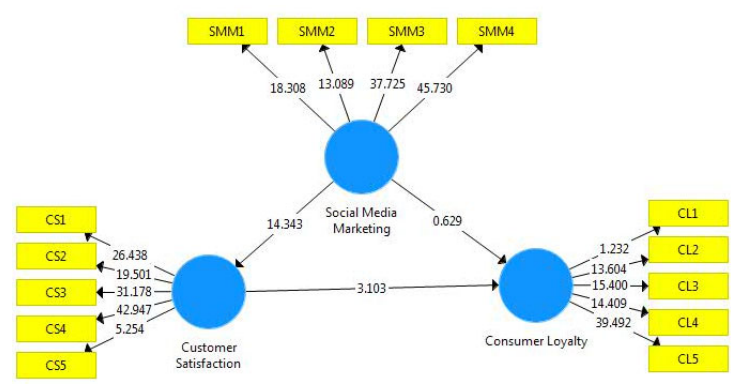

Fig. 3. Hypotheses Testing

Table 3

The summary of testing the hypotheses

\begin{tabular}{llll}
\hline Correlation & Original Sample $(\mathrm{O})$ & T Statistics & P Values \\
\hline Customer Satisfaction $\rightarrow$ Customer Loyalty & 0.429 & 3.952 & 0.001 \\
Social Media Marketing $\rightarrow$ Customer Loyalty & 0.464 & 4.051 & 0.002 \\
Social Media Marketing $\rightarrow$ Customer Satisfaction & 0.692 & 9.258 & 0.005 \\
\hline
\end{tabular}

From the value of the hypothesis testing table, it is known that all hypotheses in the study are accepted because they have a p-value below 0.05 .

\section{$4.1 f^{2}$ Effect Sizes Evaluation}

Hair et al. (2017) explained that the guidelines for assessing $\mathbf{f}^{2}$ are that values of $0.02(=$ small), 0.15 (= moderate), and 0.35 (= large), respectively, represent small, medium, and low effects.

Table 4

$\mathrm{f}^{2}$ Effect Sizes Evaluation

\begin{tabular}{ccc}
\hline & Satisfaction & 0.26 \\
Customer Loyalty & 0.22 \\
Social Media Marketing & 0 \\
\hline
\end{tabular}

For the Customer Loyalty variable, the $\mathbf{f}^{2}$ value of 0.26 represents a large effect, for the Social Media Marketing variable, the $\mathbf{f}^{2}$ value of 0.28 represents a large effect

\section{$4.2 Q^{2}$ Evaluation}

$\mathrm{Q}^{2}$ value is greater than 0 indicates that the model has predictive relevance for certain endogenous constructs. Conversely, values of 0 and below indicate a lack of predictive relevance (Hair et al., 2017).

Table 5

$\mathrm{Q}^{2}$ Evaluation

\begin{tabular}{cc}
\hline Construct & $\mathrm{Q}^{2}$ \\
\hline Customer Loyalty & 0.506 \\
Customer satisfaction & 0.521 \\
\hline
\end{tabular}


The value of $\mathrm{Q}^{2}$ for the Customer Loyalty variable is $0.506>0.000$, meaning that this variable has predictive relevance. The $\mathrm{Q}^{2}$ value of the Customer satisfaction variable is $0.521>0.000$, meaning that this variable has predictive relevance.

\section{Discussion}

\subsection{The first hypothesis: The effect of social media marketing on e-commerce consumer satisfaction}

Based on the results of the SEM analysis, it was found that the p value was $0.001<0.050$ so it was concluded that social media marketing had a positive and significant effect on e-commerce consumer satisfaction. Social media marketing has a significant influence on satisfaction. These results are in line with previous research conducted by Arghashi et al. (2021), Azizan et al. (2019), Barreda et al. (2020) and Bilgin et al. (2018) regarding the influence of social media marketing in the ecommerce industry. It is suspected that e-commerce consumers will feel satisfied if they have consumed the product/service. Consumer satisfaction does not immediately occur when they see e-commerce site advertisements on social media.

\subsection{The second hypothesis: The effect of social media marketing on e-commerce consumer loyalty}

Based on the results of the SEM analysis, it was found that the p value was $0.002<0.050$ so it was concluded that social media marketing had a positive and significant effect on consumer loyalty e-commerce. there is a significant influence between social media marketing and loyalty. These results are in line with previous studies conducted by Chen et al. (2011), Cheung et al. (2019), Gökerik et al. (2018), Pramono et al. (2021), Rudyanto et al. (2021a), Wijayaa et al. (2021), Yuliantoro et al. (2019) which state that social media marketing activities can increase consumer confidence in e-commerce. Respondents felt that the use of one of the social media marketing features, namely being able to discuss/exchange opinions from Instagram users on e-commerce is something that is considered in social media marketing. Delima et al. (2019) and Gökerik et al. (2018) revealed that one way to build consumer trust is to provide a special channel for consumers who want to discuss/exchange opinions and submit complaints and suggestions. By managing social media professionally, it will create trust in the brand managed by the social media

\subsection{The effect of satisfaction on e-commerce consumer loyalty}

Based on the results of the SEM analysis, it was found that the $p$ value was $0.005<0.050$ so it was concluded that satisfaction had a positive and significant effect on e-commerce consumer loyalty. Satisfaction has a significant effect on loyalty. This is in accordance with previous studies conducted by Jamali et al. (2018), Judson et al. (2012), Musa et al. (2016) and Nisar et al. (2016) which states that satisfaction can increase consumer confidence in the online shopping industry. Based on the SEM results, the satisfaction indicator that contributes the most is satisfaction with the shopping experience in e-commerce. Respondents were satisfied with the shopping experience on e-commerce sites. Therefore, e-commerce industry players can improve and provide variety so that consumers have a pleasant shopping experience. Nobar et al. (2020), Pham et al. (2015), Savitri et al. (2022) and Seo et al. (2020) stated that satisfaction with the shopping experience on e-commerce sites can increase consumer confidence. Increasing e-commerce consumer satisfaction will have an impact on increasing consumer confidence.

\section{Theoretical implications}

The theoretical implication of this research is that social media marketing has a significant effect on e-commerce consumer satisfaction, these results strengthen and support the theory and findings of Chen et al. (2011), Cheung et al. (2019), Gokerik et al. (2018), Pramono et al. (2021), Rudyanto et al. (2021), Wijayaa et al. (2021), Yuliantoro et al. (2019) that an increase in social media marketing will encourage an increase in e-commerce consumer satisfaction positively and Social media marketing has a significant effect on e-commerce consumer loyalty. The results also support the theory and the findings of Jamali et al. (2018), Judson et al. (2012), Musa et al. (2016), Nisar et al. (2016), which indicated that an increase in social media marketing would encourage a positive and significant increase in e-commerce consumer loyalty. Satisfaction has a significant effect on e-commerce consumer loyalty, these results strengthen and support the theory and findings of Chen et al. (2011), Cheung et al. (2019), Gökerik et al. (2018), Pramono et al. (2021), Rudyanto et al. (2021), Wijayaa et al. (2021) and Yuliantoro et al. (2019) which stated that the increase in consumer satisfaction e-commerce action will encourage a positive and significant increase in e-commerce consumer loyalty.

\section{Practical Implications}

The practical implication of this research is that social media marketing has a significant effect on consumer satisfaction, management of e-commerce SMEs can maintain and increase social media marketing variables and their indicators to increase consumer satisfaction. Social media marketing has a significant effect on consumer loyalty, e-commerce SMEs management can maintain and improve social media marketing variables and their indicators to increase consumer loyalty. Social media marketing has a significant effect on consumer loyalty. Consumer Satisfaction has a significant effect on e-commerce consumer loyalty, management of e-commerce SMEs can maintain and increase the Consumer Satisfaction variable and its indicators to increase consumer loyalty. 


\section{Conclusion}

The results of this study have indicated that social media marketing has a significant effect on e-commerce consumer satisfaction, social media marketing has a significant effect on e-commerce consumer loyalty and satisfaction has a significant effect on e-commerce consumer loyalty. The study has suggestions for theoretical implications that are empirically tested, namely the influence of social media marketing, satisfaction, e-commerce consumer loyalty. The model in this study has met the requirements of the goodness of fit feasibility test so that it can provide a library reference related to e-commerce consumer loyalty. Further research can use other social media platforms. The results of this study are expected to be useful for $\mathrm{C} 2 \mathrm{C}$ (consumer to consumer) e-commerce industry players. Based on path analysis, social media marketing has a significant effect on loyalty through trust. This can indicate that social media marketing can increase consumer confidence and have an impact on shopping loyalty on e-commerce sites. The personalization dimension has the greatest value in shaping social media marketing with the biggest indicator contribution being posting content that can attract consumer interest on Instagram social media. Therefore, e-commerce industry players can post interesting content by providing useful information, so that consumers want to recommend to friends to visit the e-commerce site's Instagram account. Consumers who are interested in the information posted by e-commerce sites on social media Instagram will share the information with friends and relatives. This can indirectly expand the distribution of information and can increase consumer confidence. Social media marketing activities are able to increase consumer confidence and provide the largest contribution to e-commerce consumer loyalty. E-commerce industry players can increase consumer confidence by maintaining and increasing the accuracy of product description conformity with actual conditions. E-commerce industry players must ensure that sellers who work with industry players provide product descriptions that are in accordance with actual conditions. If the e-commerce industry can maintain and improve the accuracy of product conformity, this will increase consumer loyalty. Loyal consumers will provide benefits for e-commerce industry players in maintaining continuity in the online shopping market. This is because the biggest contribution in forming loyalty is that consumers will repurchase on e-commerce sites and will choose e-commerce sites when shopping online.

\section{References}

Arghashi, V., Bozbay, Z., \& Karami, A. (2021). An Integrated Model of Social Media Brand Love: Mediators of Brand Attitude and Consumer Satisfaction. Journal of Relationship Marketing, 1-30.

Azizan, N. S., \& Yusr, M. M. (2019). The influence of customer satisfaction, brand trust, and brand image towards customer loyalty. International Journal of Entrepreneurship, 2(7), 93-108.

Barreda, A. A., Nusair, K., Wang, Y., Okumus, F., \& Bilgihan, A. (2020). The impact of social media activities on brand image and emotional attachment: a case in the travel context. Journal of Hospitality and Tourism Technology, 11(1), 109135.

Bilgin, Y. (2018). The effect of social media marketing activities on brand awareness, brand image and brand loyalty. Business \& Management Studies: An International Journal, 6(1), 128-148.

Chen, Y., Fay, S., \& Wang, Q. (2011). The role of marketing in social media: How online consumer reviews evolve. Journal of Interactive Marketing, 25(2), 85-94.

Cheung, M. L., Pires, G. D., \& Rosenberger III, P. J. (2019). Developing a conceptual model for examining social media marketing effects on brand awareness and brand image. International Journal of Economics and Business Research, 17(3), 243-261.

Delima, A., Ashary, H. M., \& Usman, O. (2019). Influence of Service Quality, Product Quality, Price, Brand Image, and Promotion to Consumer Satisfaction Affecting on Consumer Loyalty (Online Shop). Product Quality, Price, Brand Image, and Promotion to Consumer Satisfaction Affecting on Consumer Loyalty (Online Shop)(January 1, 2019).

Gökerik, M., Gürbüz, A., Erkan, I., Mogaji, E., \& Sap, S. (2018). Surprise me with your ads! The impacts of guerrilla marketing in social media on brand image. Asia Pacific journal of marketing and logistics, 30(5), 1222-1238.

Hair Jr, J. F., Matthews, L. M., Matthews, R. L., \& Sarstedt, M. (2017). PLS-SEM or CB-SEM: updated guidelines on which method to use. International Journal of Multivariate Data Analysis, 1(2), 107-123.

Jamali, M., \& Khan, R. (2018). The impact of consumer interaction on social media on brand awareness and purchase intention! Case study of Samsung. Journal of Marketing, 114.

Judson, K. M., Devasagayam, P. R., \& Buff, C. L. (2012). Self-perceived brand relevance of and satisfaction with social media. Marketing Management Journal, 22(2), 131-144.

Musa, H., Ab Rahim, N., Azmi, F. R., Shibghatullah, A. S., \& Othman, N. A. (2016). Social media marketing and online small and medium enterprises performance: Perspective of Malaysian small and medium enterprises. International Review of Management and Marketing, 6(S7), 1-8.

Nisar, T. M., \& Whitehead, C. (2016). Brand interactions and social media: Enhancing user loyalty through social networking sites. Computers in Human Behavior, 62, 743-753.

Nobar, H. B. K., Kalejahi, H. K., \& Rostamzadeh, R. (2020). Impact of social media marketing activities on brand equity and brand commitment in the leather industry. International Journal of Business Excellence, 20(2), 191-204.

Pham, P. H., \& Gammoh, B. S. (2015). Characteristics of social-media marketing strategy and customer-based brand equity outcomes: a conceptual model. International Journal of Internet Marketing and Advertising, 9(4), 321-337. 
Pramono, R., Sondakh, L. W., Bernarto, I., Juliana, J., \& Purwanto, A. (2021). Determinants of the small and medium enterprises progress: A case study of SME entrepreneurs in Manado, Indonesia. The Journal of Asian Finance, Economics, and Business, 8(1), 881-889.

Rudyanto, R., Pramono, R., Juliana, J. (2021a). Perception of Knowledge of the Risk of the COVID -19 Pandemic Regarding Touring Intentions and Tourism Travel Recommendations. Journal of Environmental Management and Tourism, (Volume XII,Summer), 4(52), 929 - 947. DOI:10.14505/jemt.v12.4(52).08

Purwanto, A., \& Juliana (2021). The effect of supplier performance and transformational supply chain leadership style onsupply chain performance in manufacturing companies. Uncertain Supply Chain Management, 10(2), 1-8

Rudyanto, R., Pramono, R., \& Purwanto, A. (2021). The influence of antecedents of supply chain integration on company performance. Bagchi, PK \& Chun HB (2005). Supply Chain Integration: a European survey. The International Journal of Logistics Management, 16(2), 275-294.

Savitri, C., Hurriyati, R., Wibowo, L., \& Hendrayati, H. (2022). The role of social media marketing and brand image on smartphone purchase intention. International Journal of Data and Network Science, 6(1), 185-192.

Seo, E. J., Park, J. W., \& Choi, Y. J. (2020). The effect of social media usage characteristics on e-WOM, trust, and brand equity: Focusing on users of airline social media. Sustainability, 12(4), 1691.

Wijayaa, O., Sulistiyanib, S., Pudjowatic, J., Kurniasih, N., \& Purwanto, A. (2021). The role of social media marketing, entertainment, customization, trendiness, interaction and word-of-mouth on purchase intention: An empirical study from Indonesian smartphone consumers. International Journal of Data and Network Science, 5(3), 231-238.

Yuliantoro, N., Goeltom, V., Juliana, I. B., Pramono, R., \& Purwanto, A. (2019). Repurchase intention and word of mouth factors in the millennial generation against various brands of Boba drinks during the Covid 19 pandemic. African Journal of Hospitality, Tourism and Leisure, 8(2), 1-11. 
(C) 2022 by the authors; licensee Growing Science, Canada. This is an open access article distributed under the terms and conditions of the Creative Commons Attribution (CC-BY). license (http://creativecommons.org/licenses/by/4.0/). 